\title{
The total benefit of alternative assets to pension fund portfolios ${ }^{\text {is }}$
}

\author{
Jens Carsten Jackwerth ${ }^{\mathrm{a}, *}$, Anna Slavutskaya ${ }^{\mathrm{b}, 1}$ \\ a University of Konstanz, PO Box 134, 78457 Konstanz, Germany \\ b École polytechnique fédérale de Lausanne - Swiss Finance Institute, SFI@EPFL, Quartier Unil-Dorigny, CH-1015, Switzerland
}

Pension funds only quite recently have explored alternative assets, prodded by financial crises that devastated equity returns and led to low bond returns. We assess the addition of alternative assets to pension fund portfolios in terms of the total benefit derived from diversification, addition of positive skewness, and the elimination of left tails in returns. During 1994 2012, adding portfolios of hedge funds produced significantly higher total benefits than adding real estate, commodities, foreign equities, mutual funds, funds of funds, as well as some counter cyclical and non cyclical assets. Conditioning on past total benefits improves the out of sample performance even further.

Performance measurement

Certainty equivalent

Alpha

\section{Introduction}

Hedge funds with their diverse strategies have become an attractive investment tool for many institutional investors, including pension funds looking for enhanced portfolio performance due to factors such as diversification and additional alpha. A large share of pension funds increased their hedge fund holdings during the financial crisis even while a number of hedge funds failed. ${ }^{2}$ According

\footnotetext{
We thank Günter Franke, James E. Hodder, Kostas Iordanidis, Olga Kolokolova, Alberto Plazzi, and seminar participants at Konstanz University and the University of Zurich.

* Corresponding author. Tel.: +49 753188 2196; fax: +49 7531883120

E-mail addresses: jens.jackwerth@uni-konstanz.de (J.C. Jackwerth), anna.slavutskaya@epfl.ch (A. Slavutskaya).

1 Tel.: +41216931974.

2 According to the National Association of Pension Funds, pension funds in the United Kingdom substantially increased their allocation in hedge funds from $1.8 \%$ in 2009 to $4.1 \%$ in 2011 .
} 
to the survey provided by Preqin (2014), investments into the hedge fund industry have continued to grow in recent years, with much inflow from institutional investors; over $80 \%$ of these investors express satisfaction with the hedge fund performance and are willing to maintain or even increase their hedge fund allocations. ${ }^{3}$ However, while many pension funds continue to be enthusiastic about hedge funds, there are also remarkable dropouts. Calpers, one of the largest retirement funds in the United States, recently pulled out its $\$ 4$ billion investments in hedge funds. ${ }^{4}$ Apparent reasons were that hedge funds are too opaque and too expensive. Complexity and high fees are also the main reasons for the Dutch pension fund PFZW to stop investing in hedge funds. Despite the examples of Calpers and PFZW, no dramatic investment shift overall has occurred. For example, around 50\% of all U.S. public pension funds are exposed to hedge funds because they still worry about the future performance of stocks (Preqin, 2014).

We thus want to investigate the overall attractiveness of adding hedge funds to pension fund portfolios while weighing the costs and benefits. We do so based on a sample of U.K. funds available to individuals with a personal defined contribution pension plan, where we take into account that exposure to hedge funds is only around $515 \%{ }^{5}$

According to Myners' (2001) review set up by the U.K. government, early reluctance of pension fund trustees and investment consultants to diversify their portfolios beyond traditional assets is partly due to their misconception that long only equity investing should be profitable in the long run despite any occasional downturns. After a series of significant market downturns, the long only equity strategy was augmented by increased bond allocations which, together with the lower risk, inevitably led to lower returns. After these successive failures, pension funds turned to alternative investments and in particular to hedge funds; however, choosing the right hedge fund for addition to a pension fund portfolio is challenging. In general, institutional investors tend to hold hedge fund allocations in order to preserve capital, strengthen diversification, and reduce volatility. The com plexity of hedge fund strategies and their dynamic nature make performance assessment difficult. The de facto standard of hedge fund performance measurement is the alpha within the Fung and Hsieh (2001) seven factor model. The resulting estimated intercept of the model, alpha, is then used to rank hedge funds. Investors chase alpha by investing more into hedge funds with high historical alpha (Fung et al., 2008).

Alas, one has to wonder about the quality of estimated hedge fund alpha due to short samples [typically 36 returns from which 8 parameters need to be estimated in the Fung and Hsieh (2001) model], omitted variables, and the poorly specified linear factor model (the $\mathrm{R}$ squared is typically $\sim 40 \%$ ). Further, the persistence of alpha is low, which means that historically high alpha funds will not necessarily exhibit such high alpha again in the future (Capocci and Hübner, 2004).

Even though alpha remains an important target of investors, there are other dimensions of portfolio performance about which investors care, such as diversification benefits, the addition of positive skewness, and the reduction of fat (left) tails of the portfolio returns distribution. Less tan gible benefits such as having a hedge fund manager of high reputation or personal tailoring of pro ducts to the investors should also matter to investors but are harder to quantify. Goetzmann et al. (2007) show in their simulation studies that alpha does not penalize for under diversification.

In order to measure the total benefit to pension fund investors, we suggest using changes in the manipulation proof performance measure (MPPM) as proposed in Goetzmann et al. (2007). The MPPM is closely related to the certainty equivalent value of the fund returns under a power utility function, which is the risk free return that yields the same expected utility as investment into the pension fund. We also employ the almost stochastic dominance approach (ASD) proposed by Leshno and Levy (2002) and used in Bali et al. (2009) and Bali, Brown, and Demirtas (2012, 2013). ASD is utility based (as is MPPM) but does not require parametric specification of investors' preferences. Furthermore, we use the Sharpe ratio and factor model alpha as alternative performance measures in

\footnotetext{
${ }^{3}$ Preqin's (2014) hedge fund survey is based on 14,100 hedge funds with 6300 manager profiles, as well as detailed information on over 4400 active investors in hedge funds.

${ }^{4}$ Financial Times, September 20, 2014, page 8, "California Calls Time."

${ }^{5}$ We still call our sample one of pension funds even though it technically covers pension funds as well as mutual funds that can be used for pension investments.
} 
all our main tests and use even more measures in our robustness analyses. Results are largely unaffected by the choice of performance measure.

We begin by measuring the performance (MPPM) of pension fund portfolios without additional alternative assets. We then determine the returns of pension fund portfolios with alternative assets by selling $10 \%$ of the total portfolio (in proportion) and investing these funds into an alternative asset. While there is a trend for pension funds to increase allocations in hedge funds, very few pension funds allocate more than $515 \%$ of total assets to hedge funds, as in many countries there are restrictions on such risky investments, see International Monetary Fund (2004) and Stewart (2007). We also measure the performance (MPPM) of the augmented pension fund portfolios and compare that to the performance of the original pension funds.

We consider several alternative assets a pension fund manager might invest in: a portfolio of random hedge funds, a portfolio of mutual funds, the risk free asset, a real estate index, a commodity index, a foreign equity index, and a random fund of funds. While these are mainly pro cyclical assets, we also test against counter cyclical (and non cyclical) assets such as an inverse exchange traded fund (ETF), precious metals, portfolios of put options with a targeted market beta of 1 , and a consumer staples index. Our sample period is from February 1994 to December 2012.

We contribute to the literature in three ways. First, we document that adding a portfolio of random hedge funds to a pension fund (hereafter, "the hedge fund portfolio strategy") on average significantly increases the MPPM of the pension fund ( $\triangle M P P M=0.79 \%$ annualized) during 19942012 . Our baseline (power utility) risk aversion coefficient for the MPPM is $\gamma=3{ }^{6}$ This $\triangle M P P M$ is achieved by replacing only $10 \%$ of the pension fund with a hedge fund investment; the $\triangle M P P M$ would be $6.4 \%$ for a $100 \%$ investment into a random portfolio of hedge funds, more than eight times larger than $0.79 \%$. The hedge fund portfolio strategy turns out to be significantly more beneficial than adding alternative assets, such as real estate, commodities, foreign equity, mutual funds, inverse ETFs, consumer staples, portfolios of options with targeted market beta of 1, or fund of funds. Measuring the out of sample performance in terms of the Sharpe ratio, alpha, or value at risk gives similar rankings of the alter native assets.

Results turn out to be stronger once we condition on in sample information and then measure the out of sample $\triangle M P P M$ over and beyond the random hedge fund portfolio strategy: a naïve optimi zation strategy of selecting only hedge funds with the largest $5 \%$ in sample $\triangle M P P M$, for example, achieves an $\triangle M P P M$ of $1.05 \%$ annualized, significantly larger than the random hedge fund strategy with an $\triangle M P P M$ of $0.79 \%$. While the sorts based on $\triangle M P P M$, ASD, mean, and alpha perform best compared to a random strategy $(0.26 \%, 0.25 \%, 0.25 \%$, and $0.31 \%$, respectively), other performance measures show less improvement (around 0.10 0.20\%). Kurtosis ( $0.01 \%$ ) and standard deviation $(0.00 \%)$ perform worst.

Our second contribution details the conditions under which adding a portfolio of hedge funds is more profitable for a pension fund. Our empirical evidence suggests that hedge funds work best during recessions. This is consistent with the initial role of hedge funds as a source of downside protection. However, as with any protection, this comes at a cost of lower performance during up markets.

$\triangle M P P M$ was $1.98 \%$ during the recession in 2001 and $3.07 \%$ during the recent financial crisis. Hedge funds provide a better downside protection during market downturns than traditional investments, such as stocks and bonds or other alternatives like mutual funds, real estate, commodities, and foreign equities. Some counter cyclical assets like the gold index and put portfolios, however, perform rather well during recessions, which is due to their negative correlation with the overall state of the economy.

Investigating different hedge fund styles, we show that commodity trading advisors/managed futures hedge funds on average add the most to a portfolio of pension funds ( $\triangle M P P M$ of $0.32 \%$ compared to a random hedge fund strategy), followed by sector trading, distressed, and global macro strategies. Emerging markets funds add the least ( $\triangle M P P M$ of $0.21 \%$ ).

Exploring the heterogeneity across pension funds, we find that pension funds with large equity allocations benefit most from adding a hedge fund. Diversified pension funds as well as funds tilted

\footnotetext{
${ }^{6}$ These results are insensitive to reasonable changes in the risk aversion coefficient used to compute the certainty equivalent or to the exact composition of the benchmark; see the robustness section for details.
} 
towards real estate benefit less, while pension funds with large bond holdings benefit the least. In practice, some pension funds might not be allowed to invest in hedge funds. This is typically pre determined by the investment style criteria. In a robustness test, we thus restrict our sample to only those pension funds that are allowed to invest into alternative investments (including hedge funds). The results on this restricted sample confirm our main findings. The benefit of adding hedge funds to pension funds $(\triangle M P P M)$ increases in relation to pension fund size but only up to a point, beyond which the benefits of adding hedge funds to very large pension funds decreases again. Such decreasing returns to scale might well be an explanation for the recent disinvestments from hedge funds of large pension funds in the U.S. and Europe.

Our third contribution to the literature is to show that $\triangle M P P M$ is more persistent than Fung and Hsieh's (2001) alpha over a one year horizon. For longer horizons, neither measure is persistent any longer, which could be due to the reduced sample size as we partition our 19 years of data into fewer but longer intervals. Less pronounced persistence in alpha can be due to by the occurrence of a small sample bias (in one extreme case we estimate 8 parameters based on only 12 observations).

Our results are robust to a battery of challenges. We add a single random hedge fund instead of a portfolio of hedge funds, use de smoothed hedge fund returns, change the risk aversion coefficient of the MPPM calculation up and down, plus conduct a number of additional minor changes in our methodology.

Based on our literature review in Section 2, we develop the hypotheses and introduce the econometric methodology for testing our performance measure in Section 3. All data are presented in Section 4. A discussion of the results follows in Section 5, while robustness checks are analyzed in Section 6. We conclude in Section 7.

\section{Literature}

Our work closely connects to the selection of a performance measure for pension and hedge fund evaluation. Performance measures can be split into three main groups. In the first group, we have the mean variance inspired ratios such as the Sharpe ratio. The second group encompasses factor models. The final group consists of other utility based performance measurements to which the MPPM belongs and where we also subsume stochastic dominance based measures.

Various ratios have been suggested as performance measures, often much earlier than the advent of hedge funds, and they are still in widespread use. We use the measures of Sharpe (1966) and Sortino, van der Meer, and Plantinga (1999). Even though ratios are widely used in the hedge fund literature (Ackermann, McEnally, and Ravenscraft, 1999; Liang, 1999), they have also been criticized, as for example by Kao (2002) and Amin and Kat (2003). In most of the ratios, normally distributed returns are assumed. Use of derivatives and dynamic strategies within hedge funds can create non normally distributed returns with non zero skewness and fat tails. In addition, hedge fund returns can exhibit serial correlation, which could lead to over estimated Sharpe ratios (Lo, 2002).

Due to the problems associated with ratios, performance assessment for hedge funds is firmly centered around the alpha within the factor models of Fung and Hsieh (2001) or Agarwal and Naik (2004):

$$
r_{t} \quad r_{f, t}=\alpha+\sum_{k}^{K}{ }_{1} \beta_{k} X_{k, t}+\varepsilon_{t},
$$

where $\left(r_{t} r_{f, t}\right)$ is a hedge fund return at time $t$ in excess of the risk free rate, $\alpha$ is the abnormal return, $X_{k, t}(k=1, \ldots, K)$ are the $\mathrm{K}$ relevant risk factors at time $t, \beta_{k}(k=1, \ldots, K)$ are the risk exposures to be estimated, and $\varepsilon_{t}$ is an error term.

However, even if a hedge fund delivered high alpha in the past, it is questionable whether the hedge fund can also deliver comparable alpha in the future other than by chance. While some authors find significant persistence in alpha (Agarwal and Naik, 2000; Edwards and Caglayan, 2001), others find limited evidence for such persistence (Capocci and Hübner, 2004). Berk and Green (2004) pro vide a theoretical argument for alpha being driven down to zero in a mutual fund setting caused by diminishing mutual fund performance in turn due to fund flows. Still, without such diminishing returns, managerial skill could persist over time and should then lead to persistence in alpha. 
Kosowski et al. (2007), Naik et al. (2007), Jagannathan et al. (2010), and Berk and van Binsbergen (2013) use factor models to determine if alpha truly does exist or is simply due to estimation error (and thus luck). ${ }^{7}$ Within measures based on factor models, we also consider the timing skill esti mators of Treynor and Mazuy (1966) and Henriksson and Merton (1981). Alas, none of these papers moves beyond the factor model structure. Thus, other dimensions of total benefit, such as diversifi cation, skewness, and tail risk might be omitted unless they are being captured by the few factors (typically around 8) used in such models.

Of the additional dimensions of total benefit, diversification benefits due to investing into man aged futures have been argued by Amin and Kat (2002), Lhabitant and Learned (2002), Kat (2004), and Rollinger (2012). However, those authors look only at diversification and do not introduce a performance measure capable of measuring the other dimensions of total benefit.

To broadly measure total benefit, we follow Goetzmann et al. (2007) and use the MPPM:

$$
M P P M=\frac{1}{\left(1 \frac{\gamma}{1}\right) \Delta t} \ln \left(\frac{1}{T} \sum_{t}^{T}\left[\left(1+r_{t}\right) /\left(1+r_{f, t}\right)\right]^{1-\gamma}\right),
$$

where $T$ is the total number of observations, $\Delta t$ is the length of time between observations, $r_{t}$ is the hedge fund return at time $t, r_{f, t}$ is the risk free rate, and $\gamma$ is the risk aversion coefficient.

Goetzmann et al. (2007) showed the MPPM to be robust to manipulations of the underlying return distribution, to the introduction of time variation in the underlying distribution, and to excessive use of dynamic trading strategies by fund managers. Brown et al. (2008) apply their measure to hedge funds but solely assess its quality as a manipulation proof measure, confirming the theoretical pre dictions of Goetzmann et al. (2007). Bali et al. (2013) use the MPPM measure as well as the concept of almost stochastic dominance (ASD) of Leshno and Levy (2002) to investigate whether hedge funds outperform stock or bond markets. They find that the MPPM and ASD generate robust and consistent rankings among hedge fund strategies and give the best results in deciding between hedge funds and stocks and bonds compared to traditional performance measures like the (modified) Sharpe ratio, the Treynor ratio, the Sortino ratio, and the Calmar ratio. However, Bali et al. (2013) only use pure hedge fund investments (100\%). Yet such investment is unrealistic for pension funds, which have some conservative base allocation to stocks and bonds. Realistically, pension fund managers seem more concerned about the marginal effect of adding a limited investment (typically only 5 15\%) in alter native investments (possibly hedge funds but also real estate, commodities, foreign equity, mutual funds, fund of funds, and others) to their portfolio. We investigate such marginal effects in terms of the MPPM and ASD.

\section{Hypotheses and methodology}

We test six hypotheses with respect to $\triangle M P P M$ in its capacity to measure the total benefit of adding alternative assets to pension fund portfolios.

\subsection{The hedge fund portfolio strategy adds total benefit ( $\triangle M P P M)$}

In our first hypothesis, we posit that adding hedge funds as an alternative asset does indeed confer benefits to pension funds, for example by increasing diversification, adding excess returns (alpha), adding positive skewness, or decreasing the chance of negative returns. To test our hypothesis, we consider each pension fund from our database in turn. As an alternative asset, we add a random portfolio of hedge funds, a random portfolio of mutual funds, the risk free asset, a real estate index, a commodity index, a foreign equity index, and a random fund of funds. We do so by computing an augmented pension fund return based on investing $90 \%$ into the original pension fund portfolio and the remaining $10 \%$ into one of the seven alternative assets.

\footnotetext{
${ }^{7}$ See also Ferson and Lin (2013) on the use of alpha in a world with heterogeneous investors who differ in their
} preferences. 
For the random hedge fund portfolio strategy, we start with the 25th monthly return, so that we keep a sample of 24 prior returns which, if later needed, we can use for conditioning information. We randomly pick out of all existing hedge funds (with at least 24 prior returns) 20 hedge funds and denote the sum of the equally weighted 25th returns as $r_{1}$. Then, we move one month forward and check whether the previously chosen 20 hedge funds have not been delisted from the database. If any of these hedge funds has been delisted from the database, we put a zero return instead of the missing return for this hedge fund and randomly pick another hedge fund with at least 24 past returns as a future replacement. ${ }^{8}$ We repeat this procedure until the end of our sample, which provides us with a time series $\left(r_{1}, r_{2}, \ldots, r_{T}\right)$ of $T$ returns of a portfolio of 20 random hedge funds. ${ }^{9}$

We similarly construct the time series for a portfolio of 20 random mutual funds. For a random fund of funds, we only pick a single fund of funds since it already constitutes a portfolio of hedge funds. For the other alternative assets, where only a single index exists, we simply use that index as our time series.

To test our first hypothesis, we calculate $\triangle M P P M$ as the MPPM of the original pension fund portfolio minus the MPPM of the hedge fund portfolio strategy. We repeat the random draws of 20 hedge funds and recalculate $\triangle M P P M$ for each pension fund in our database (2529 funds in total). This generates a cross section of $\triangle M P P M$ values. We can then use a paired $t$ test for the mean of the $\triangle M P P M$ values being significantly different from zero, which controls for the correlation between the MPPM values.

\subsection{Outperformance of the random hedge fund portfolio strategy}

In our second hypothesis, we sharpen the first hypothesis by positing that the addition of alter native assets should confer benefits on the pension fund but that the benefits of adding hedge funds is even greater. The idea here is that hedge funds can undertake any number of investments and are thus more diversified than the "single strategy" alternative, where investments are only made into very specific asset classes (a random portfolio of mutual funds, the risk free asset, a real estate index, a commodity index, a foreign equity index, or a random fund of funds).

To test the second hypothesis, we calculate $\triangle M P P M$ as the MPPM of the competing strategy (90\% weight in the pension fund plus $10 \%$ weight in one of the alternative assets) minus the MPPM of the hedge fund portfolio strategy (90\% weight in the pension fund plus $10 \%$ weight in a portfolio of random hedge funds). We repeat this calculation for each pension fund in the database. Similarly to the first hypothesis, we use $t$ test for the cross sectional mean of $\triangle M P P M$.

\subsection{Conditioning on in sample information}

Our third hypothesis is based on the notion that the benefits conferred by hedge funds exhibit some persistence over time. Thus, we posit that adding hedge funds which in sample add total benefits to pension funds will continue to do so out of sample. Thus, limiting the set of hedge funds from which to randomly pick by using in sample information should improve investment perfor mance. In particular, conditioning on past $\triangle M P P M$ should yield significantly higher out of sample $\triangle M P P M$ than conditioning on other traditional performance measures, which only partially account for the total benefits accruing to the investor. ${ }^{10}$

\footnotetext{
${ }^{8}$ From Hodder et al. (2013) we know that a delisting return is similar to an average hedge fund return. Thus, we are conservative here when we use a zero return instead. However, in order to verify how sensitive our results are to delistings, we use significant negative returns instead of missing ones, i.e., $-10 \%,-20 \%$, etc. instead of $0 \%$. Our results start to vanish at $-23 \%$ : even though adding a portfolio of hedge funds is still beneficial to a pension fund, other assets appear to be as profitable in terms of MPPM as hedge funds (e.g., the risk-free asset, commodities, foreign equities, funds of funds).

9 Our choice of 20 hedge funds is driven by two reasons. First, from a private conversation with a hedge fund and fund of funds manager, we found out that 20 is a typical value for the number of hedge funds into which a pension fund invests. Second, according to Lhabitant and Learned (2002), 20 hedge funds are enough to provide reasonable diversification for naïvely constructed portfolios of hedge funds. Hodder, Jackwerth, and Kolokolova (2013) use 15 hedge funds to form their fund of funds.

${ }^{10}$ Such conditioning should work better depending on the persistence of the information employed. We investigate persistence in more detail in the next hypothesis.
} 
To test our third hypothesis, we calculate $\triangle M P P M$ as the MPPM of the conditioned strategy (90\% weight in the pension fund plus $10 \%$ weight in a random hedge fund portfolio drawn from the more limited, conditioned set) minus the MPPM of the hedge fund portfolio strategy (90\% weight in the pension fund plus $10 \%$ weight in a portfolio of random hedge funds). We condition on the extreme $5 \%$ in sample values of the quantity of interest (e.g., the highest $\triangle M P P M$ ), based on the 24 returns before the month for which we want to pick a return. We then randomly pick 20 hedge funds out of that conditional set. We repeat this calculation for each pension fund in the database and use a paired $t$ test for the mean of the $\triangle M P P M$ values being significantly different from zero.

For the third hypothesis, we use three different sets of conditioning information:

1. First, we use various performance measures: total benefit (MPPM), almost second order stochastic dominance (ASSD), ${ }^{11}$ alpha estimates from the seven factor model of Fung and Hsieh (2001), changes in the first four moments of the augmented pension fund portfolio over the original portfolio, and the following traditional performance measurements: Sharpe (1966), Sortino et al. (1999), information ratio, Henriksson and Merton (1981), and Treynor and Mazuy (1966). We provide all formulas in the Appendix.

2. Second, we condition on the hedge fund's investment style, namely: equity long/short, emerging markets, fixed income, global macro, distressed, CTA/managed futures, event driven, or multi strategy.

3. Third, we condition on the pension fund's investment strategy: equity, fixed income, diversified, or real estate.

\subsection{Total benefit is more persistent than alpha}

Our fourth hypothesis concerns the persistence of hedge fund performance, which could be due to enduring information spillovers associated with innovative trading strategies or emerging sectors (Glode and Green, 2011). Due to numerous problems with the estimation (e.g., large standard errors, omitted factors, misspecified factor models), alpha is not a reliable measure of fund performance and is subject to significant biases. We thus expect that $\triangle M P P M$, which is less prone to estimation errors, will show more persistence than alpha.

For the fourth hypothesis, we consider the persistence of consecutive periods of $12,24,48$, and 72 months. We detail the method for the 24 month period; the alternative lengths follow the same pattern. We use moving windows of 24 months, starting with the 1 st, the 13 th, the 25 th, ... obser vation. Each of these windows is divided into two 12 month sub periods: a formation period (months 1 12) and an evaluation period (months 1325 ). To each pension fund $i$, which survives throughout the whole period, we add a random portfolio of hedge funds and compute the $\triangle M P P M$ during the formation period (denoted as $\triangle M P P M_{1 i}$ ) and the evaluation period (denoted as $\triangle M P P M_{2 i}$ ). Finally, we regress $\triangle M P P M_{2 i}$ on $\triangle M P P M_{1 i}$ :

$$
\triangle M P P M_{2 i}=a_{M P P M}+b_{M P P M} \triangle M P P M_{1 i}+\omega_{i},
$$

where $a_{M P P M}, b_{M P P M}$ are the parameters to be estimated, and $\omega_{i}$ is an error term. We run this regression on each of our 24 month periods and also jointly in a stacked regression. For total benefit (MPPM) to be persistent, the slope coefficient $b_{M P P M}$ should be positive and significant.

We repeat this study for the estimated alpha from a seven factor Fung and Hsieh (2001) model:

$$
\alpha_{2 i}=a_{\alpha}+b_{\alpha} \alpha_{1 i}+v_{i}
$$

where $\alpha_{1 i}\left(\alpha_{2 i}\right)$ are the alpha estimates in the formation (evaluation) period for fund $i ; a_{\alpha}, b_{\alpha}$ are the parameters to be estimated, and $v_{i}$ is an error term.

${ }^{11}$ As described by Bali et al. (2009) and Levy et al. (2010), for the empirical SSD violation area, the critical value $\varepsilon_{2}^{*}$ is obtained from experimental studies and found to be $3.2 \%$. As many hedge fund-augmented portfolios almost second order stochastically dominate the original pension fund portfolios, we additionally use the $t$-statistic from Davidson and Duclos (2000): the hedge funds are being picked based on the highest $t$-statistic. 


\section{Data}

U.K. pension fund returns are extracted from the Morningstar database. Our sample includes pension funds and mutual funds eligible for pension investment. For our calculations, we use pension funds that survive through the period from February 1994 to December 2012, which leaves us with 2529 out of some 22,000 pension funds. Taking the long sample allows us to look at the variation in the total benefit for each pension fund across time and especially during different market states. We are aware that this may lead to a look ahead bias. Therefore, we compare the selected funds to all funds in the database. The results of the comparison are presented in Table 1, Panel A. Given the small differences in the main moments, we consider our reduced sample representative for the subsequent analysis.

Instead of our requirement that pension funds remain active during the entire sample period, we also show that our results are robust if pension funds are present for only 25 or 13 months. Here, we use rolling windows of 24 or 12 months to construct our portfolios and then measure the perfor mance one month later. We shift the window one month at a time and compute the MPPM based on the resulting time series of cross sectional averages. The results do not change for the 24 month window and stay qualitatively the same even for the 12 month window.

We repeat our study without any filtering (i.e., we do not restrict pension funds to survive until the end of our sample period). In this case, we use 24 months for picking a random hedge fund portfolio

Table 1

Descriptive statistics.

The summary statistics are the equally-weighted, cross-sectional averages, standard deviations, and medians of the: mean monthly return, $\mu$; the standard deviation of monthly returns, $\sigma$; the skewness, Skewness; the excess kurtosis, Kurtosis; the minimum of the monthly returns, Minimum; the maximum of the monthly returns, Maximum; and the number of months of returns available in the sample. The sample is from February 1994 to May 2012. Panel A covers pension funds from the reduced sample and the difference in the mean of moments with the full sample, Panel B covers hedge funds, and Panel C covers mutual funds.

\begin{tabular}{|c|c|c|c|c|c|}
\hline & Average & $\begin{array}{l}\text { Standard } \\
\text { deviation }\end{array}$ & $5 \%$ quantile & $\begin{array}{c}95 \% \\
\text { quantile }\end{array}$ & $\begin{array}{c}\text { Difference } \\
\text { with full } \\
\text { sample }\end{array}$ \\
\hline$\mu$ & 0.0048 & 0.0017 & 0.0020 & 0.0073 & 0.0004 \\
\hline$\sigma$ & 0.0414 & 0.0126 & 0.0241 & 0.0616 & -0.0094 \\
\hline Skewness & -0.5104 & 0.3605 & -0.9598 & -0.0259 & 0.0201 \\
\hline Kurtosis & 4.9891 & 3.0696 & 3.2472 & 6.8576 & 0.6795 \\
\hline Minimum & -0.1741 & 0.0584 & -0.2626 & -0.0899 & -0.0075 \\
\hline Maximum & 0.1283 & 0.0423 & 0.0746 & 0.1986 & 0.0019 \\
\hline \multicolumn{6}{|c|}{ Panel B. Mutual fund returns (total of 159,465 ) } \\
\hline & Average & \multicolumn{2}{|c|}{ Standard deviation } & $5 \%$ quantile & 95\% quantile \\
\hline$\mu$ & 0.0046 & \multicolumn{2}{|c|}{0.0072} & -0.0037 & 0.0134 \\
\hline$\sigma$ & 0.0510 & \multicolumn{2}{|c|}{0.0385} & 0.0131 & 0.0938 \\
\hline Skewness & -0.4790 & \multicolumn{2}{|c|}{0.6378} & -1.2802 & 0.2997 \\
\hline Kurtosis & 4.6969 & \multicolumn{2}{|c|}{3.8939} & 2.4212 & 8.4172 \\
\hline Minimum & -0.1609 & \multicolumn{2}{|c|}{0.0852} & -0.3075 & -0.0387 \\
\hline Maximum & 0.1333 & \multicolumn{2}{|c|}{0.2918} & 0.0379 & 0.2620 \\
\hline \multicolumn{6}{|c|}{ Panel C. Hedge fund returns (total of 16,270 ) } \\
\hline & Average & \multicolumn{2}{|c|}{ Standard deviation } & $5 \%$ quantile & 95\% quantile \\
\hline$\mu$ & 0.0076 & \multicolumn{2}{|c|}{0.0138} & -0.0036 & 0.0223 \\
\hline$\sigma$ & 0.0443 & \multicolumn{2}{|c|}{0.0921} & 0.0095 & 0.1073 \\
\hline Skewness & -0.1769 & \multicolumn{2}{|c|}{1.3076} & -2.2273 & 1.6306 \\
\hline Kurtosis & 6.4167 & \multicolumn{2}{|c|}{7.0086} & 2.4142 & 16.5050 \\
\hline Minimum & -0.1234 & \multicolumn{2}{|c|}{0.1111} & -0.3350 & -0.0165 \\
\hline Maximum & 0.1444 & \multicolumn{2}{|c|}{0.7206} & 0.0250 & 0.3844 \\
\hline
\end{tabular}


and store the return of the pension fund augmented portfolio in month 25 . In month 25 , we use the average return of all available pension fund portfolios and repeat our analysis one month further. In the end, we have a time series of average pension fund returns (augmented by a hedge fund portfolio and alternative assets) and we estimate the MPPM of these return series. Our results stay robust to this procedure. Alternatively, we use a year by year averaging. In this case, we condition the pension fund to survive for at least 12 months (which is not as restrictive as our initial filter) and evaluate the MPPMs for the 12 month periods. In the end, we take the average of these MPPMs. Again, our results stay qualitatively unchanged.

Mutual fund returns are extracted from the Morningstar database and account for 159,465 indi vidual funds. The descriptive statistics are in Table 1, Panel B. Compared to the hedge funds, mutual funds demonstrate smaller average returns, kurtosis, and skewness, but larger standard deviation.

For hedge fund information, we use the MOAD database described in Hodder et al. (2013). MOAD is a merged database of six commercially available databases (CISDM, Barclays, TASS, HFR, Altvest, and Eurekahedge), i.e., the data and empirical results based on the data can be considered representative of the hedge fund industry. We use only USD denominated, net of fees returns, which leaves us with 16,270 hedge funds. The descriptive statistics of our sample are presented in Table 1, Panel C. We document excess kurtosis and left skewness in hedge fund returns, suggesting that returns often are not normally distributed. Also, returns exhibit positive serial correlation.

Hedge funds differ from other asset classes in many aspects. One of them is the absence of strict regulation. This leads to database biases, as reporting is voluntary. We address those biases as follows. First, our joint database is free of survivorship bias because it contains both live and dead funds. Second, to control for the instant history bias of funds being entered with historical data, we delete the first 12 months of each hedge fund's returns. We compute our main results on the reported returns as we find them in the database. However, our results are robust to using de smoothed returns; see Getmansky et al. (2004) and Section 6, Robustness. For funds of funds, we extract the USD denominated, net of fees returns in a similar fashion to the hedge fund returns from our database and are left with 5080 funds of funds. We also use the seven factors of the Fung and Hsieh (2001) model, which are available from David A. Hsieh's Hedge Fund Data Library. ${ }^{12}$

For our alternative assets, we use a risk free rate (Datastream U.S. 3 month T bill), a real estate index (Datastream D.J. U.S. Real estate investment trusts, REITs), a commodity index (Datastream S\&P GSCI index), and a foreign equity index (Datastream MSCI EAFE). We also include counter cyclical assets such as an inverse ETF (ProShares Short S\&P500 from yahoo.finance), portfolios of out of the money put options with targeted market beta of 1 (from Constantinides et al., 2013,) ${ }^{13}$ a gold index (Datastream S\&P GSCI Gold index), as well as a non cyclical consumer staples index (Datastream S\&P 500 Consumer Staples index). The data on options and ETF returns are shorter than our main sample. The returns of put options are from February 1994 to January 2012; the returns on the inverse ETF are from June 2006 to December 2012.

\section{Results}

In this section, we present our results for each of the six hypotheses, which are repeated as the subsection titles.

\subsection{The hedge fund portfolio strategy adds total benefit}

In line with our first hypothesis, we show in the first row of Table 2 that the strategy of aug menting the original pension fund with a $10 \%$ investment in a random hedge fund portfolio generates a significant annualized improvement in MPPM of $0.79 \%(=\Delta \mathrm{MPPM})$ over the original pension fund

\footnotetext{
12 https://faculty.fuqua.duke.edu/ dah7/HFData.htm.

${ }^{13}$ In our main tables, we use the portfolios of put options with a maturity 90 days and targeted moneyness of 0.95 . However, our results stay robust to varying the maturity and moneyness.
} 
Table 2

Unconditional strategies.

The table presents the unconditional results of our MPPM analysis for a random hedge fund portfolio. We measure the (annualized) average $\triangle M P P M$ over a random hedge fund portfolio as the MPPM of the alternative asset strategy (90\% invested into the original pension fund and $10 \%$ invested into one of the alternative assets: risk-free rate, real estate, commodity, foreign equity, random fund of funds, or a random portfolio of mutual funds) minus the MPPM of the random hedge fund strategy (90\% invested into the original pension fund and 10\% invested into a random portfolio of hedge funds). We report descriptive statistics; as well as the $p$-value of the mean $t$-test, $p$-val. We also report the cross-sectional mean change in Sharpe ratio $(\Delta \mathrm{SR})$ and the change in alpha $(\Delta \alpha)$ plus the $p$-values of the associated $t$-tests. Our main sample period is from February 1994 to December 2012. The returns of put options are from February 1994 to January 2012; the returns on the inverse ETF are from June 2006 to December 2012.

\begin{tabular}{|c|c|c|c|c|c|c|c|c|c|}
\hline & \multicolumn{3}{|c|}{$\begin{array}{l}\text { Avg } \triangle \text { MPPM over } \\
\text { random hedge fund } \\
\text { portfolio }\end{array}$} & \multicolumn{2}{|c|}{$\begin{array}{l}\text { Avg } \Delta \alpha \text { over } \\
\text { random hedge } \\
\text { fund portfolio }\end{array}$} & \multicolumn{2}{|c|}{$\begin{array}{l}\text { Avg } \Delta S R \text { over } \\
\text { random hedge } \\
\text { fund portfolio }\end{array}$} & \multicolumn{2}{|c|}{$\begin{array}{l}\text { Avg } \Delta \text { VaR over } \\
\text { random hedge } \\
\text { fund portfolio }\end{array}$} \\
\hline & Mean & Std & $p$-val & Mean & $p$-val & Mean & $p$-val & Mean & $p$-val \\
\hline Original pension fund & -0.79 & 0.5 & 0 & -0.45 & 0 & -0.04 & 0 & 1.88 & 0 \\
\hline Random portfolio of mutual funds & -0.36 & 0.2 & 0 & -0.43 & 0 & -0.02 & 0 & 0.69 & 0 \\
\hline Random fund of funds & -0.17 & 0.33 & 0 & -0.13 & 0 & -0.01 & 0 & -0.06 & 0.02 \\
\hline Real estate index & -0.69 & 0.23 & 0 & -0.56 & 0 & -0.04 & 0 & 1.21 & 0 \\
\hline Commodity index & -0.36 & 0.19 & 0 & 0.01 & 0.52 & -0.02 & 0 & 0.47 & 0 \\
\hline Foreign equity index & -0.37 & 0.2 & 0 & 0.02 & 0.01 & -0.02 & 0 & 0.71 & 0 \\
\hline Risk-free rate & -0.35 & 0.21 & 0 & -0.29 & 0 & -0.04 & 0 & -0.61 & 0 \\
\hline OTM put portfolio & -1.01 & 0.47 & 0 & -0.56 & 0 & -0.12 & 0 & -2.36 & 0 \\
\hline Gold & 0.22 & 0.21 & 0 & 0.45 & 0 & 0.01 & 0 & -1.06 & 0 \\
\hline Consumer staples index & -0.22 & 0.18 & 0 & -0.11 & 0 & -0.02 & 0 & 0.39 & 0 \\
\hline Inverse ETF & -0.79 & 0.49 & 0 & -0.47 & 0 & -0.05 & 0 & 0.82 & 0 \\
\hline
\end{tabular}

portfolio without alternative assets. To appreciate the magnitude of a $\triangle$ MPPM of $0.79 \%$, note that we are conducting a marginal analysis. A pure (as opposed to marginal) strategy of going from a 100\% investment in the original pension fund to a $100 \%$ investment in a random portfolio of hedge funds leads to a $\triangle$ MPPM of $6.4 \%$, more than eight times larger than $0.79 \%$.

Repeating the analysis with the Fung and Hsieh (2001) alpha $(\Delta \alpha)$ or the Sharpe ratio $(\Delta \mathrm{SR})$ as a performance measurement generates the same results; again with zero $p$ values.

\subsection{The hedge fund portfolio strategy outperforms adding other alternative assets}

We significantly reject that adding the risk free asset $(\triangle \mathrm{MPPM}=0.35 \%)$, a real estate index ( $0.69 \%)$, a commodity index ( $0.36 \%)$, a foreign equity index ( $0.37 \%$ ), a random fund of funds ( $0.17 \%$ ), or a portfolio of random mutual funds ( $0.36 \%$ ) is as beneficial as adding a portfolio of random hedge funds. Selected counter cyclical and non cyclical assets such as portfolio of put options with market beta of $1(\Delta \mathrm{MPPM}=1.01 \%)$, an inverse ETF ( $0.79 \%)$, or an index of consumer staples ( $0.22 \%$ ) also perform worse than random hedge funds. Almost all $\Delta$ MPPM values in Table 2 are negative with zero $p$ values. The poor performance of funds of funds compared to portfolios of hedge funds seems to lie in the higher total fees. All hedge funds and funds of funds returns are observed post fee, but funds of funds have two layers of fees, one at the hedge fund level and one at the fund of funds level (Brown et al., 2008). However, adding a gold index to the pension fund portfolio increases the MPPM even more than adding a random hedge fund $(\triangle M P P M=0.22 \%)$. This is related to the fact that gold was performing exceptionally well in 20012012 . Also, once we select hedge funds according to their in sample performance, they outperform the gold index.

We also provide assessments of the different alternative assets in terms of changes to the Sharpe ratio, alpha, and value at risk (VaR, as a measure of tail risk.) The rankings of the different alternative assets do not change much when using alpha or the Sharpe ratio. We thus refrain from reporting the Sharpe ratios and alphas in the remaining tables.

When looking at the behavior of hedge fund benefits to pension funds over time, we notice the following pattern: in the states of recession, the average $\triangle M P P M$ is much higher (1.98 during the 
Table 3

Total benefit in up and down markets.

The table presents the time variation in average $\triangle$ MPPM. We measure the (annualized) average $\triangle M P P M$ over a random hedge fund portfolio as the MPPM of the alternative asset strategy ( $90 \%$ invested into the original pension fund and $10 \%$ invested into one of the alternative assets: risk-free rate, real estate, commodity, foreign equity, random fund of funds, or a random portfolio of mutual funds) minus the MPPM of the random hedge fund strategy ( $90 \%$ invested into the original pension fund and $10 \%$ invested into a random portfolio of hedge funds). We define up and down states of the market according to the NBER classification in the U.S. (Panel A) and according to the U.K. data as two successive quarters of negative economic growth (Panel B). Our main sample period is from February 1994 to December 2012. The returns of put options are from February 1994 to January 2012; the returns on the inverse ETF are from June 2006 to December 2012.

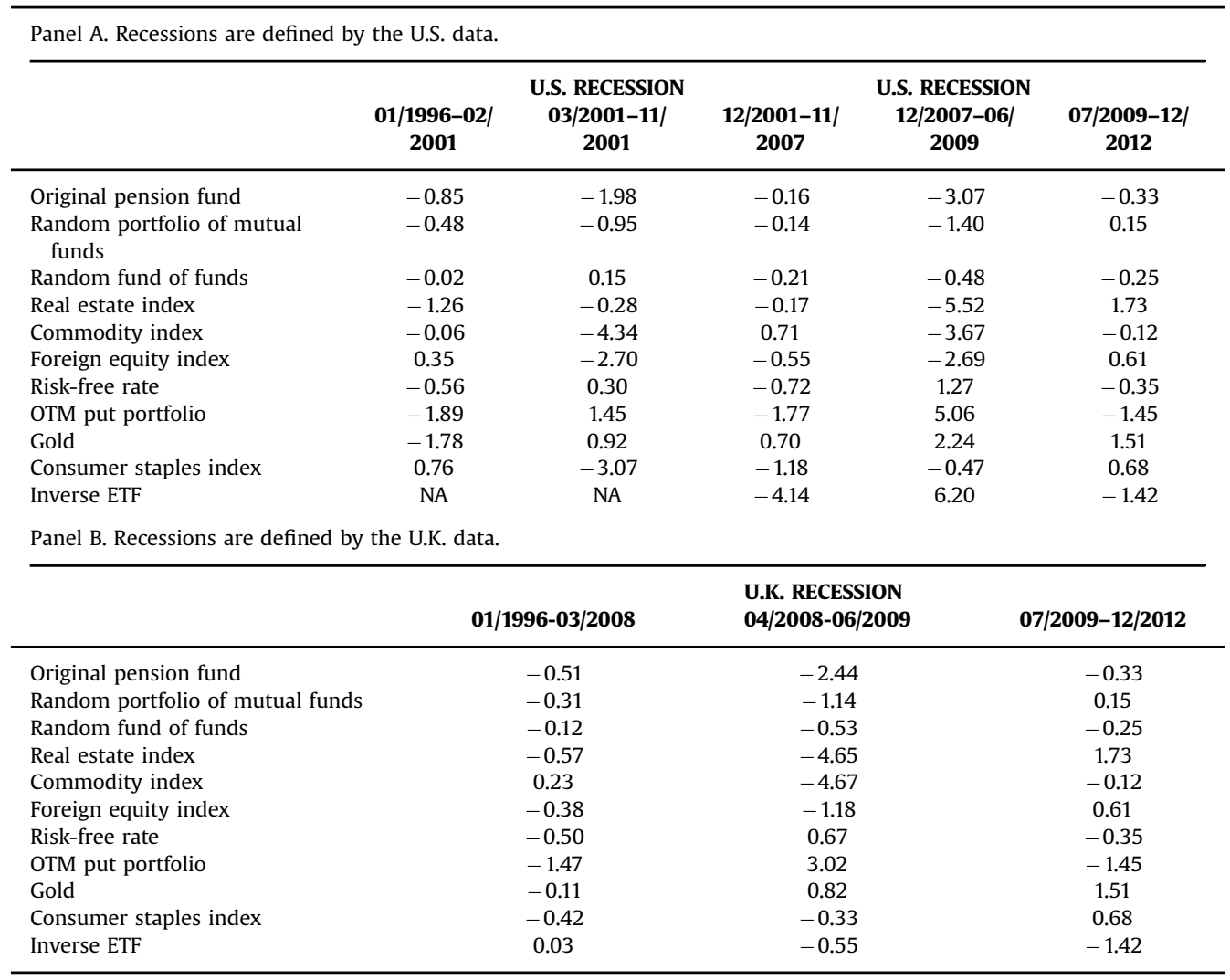

recession in 2001 and 3.07 during the recession ${ }^{14}$ from 2007 to 2009 associated with recent financial crisis, Table 3, Panel A). Brunnermeier and Nagel (2004) claim that, prior to the dotcom bubble col lapsing in March 2000, hedge funds allocated substantial shares of their capital to technology stocks, thus gaining during the up market. They were selling the stocks prior to decline and could therefore avoid the downturn, which is reflected during the period of the first recession in 2001. Outperformance during the financial crisis of 20072009 is consistent with a common belief that hedge funds do not lose as much as traditional asset classes during market downturns. Good performance of counter cyclical assets such as gold index and portfolios of put options during the crises is not surprising and is in the

\footnotetext{
html).

${ }^{14}$ We define recessions in accordance with US business cycles provided by NBER (http://www.nber.org/cycles/cyclesmain.
} 
line with the nature of these assets. Here, we refer to recessions as defined by NBER. Many asset classes including hedge funds were affected by the U.S. crises. However, as we use U.K. pension funds, we also determine economic downturns in the U.K. as two successive quarters of negative economic growth. There is only one U.K. crisis period in recent history: 2008:Q2 2009:Q2. During this period, hedge funds tended to significantly outperform other assets: the average $\triangle M P P M$ is $2.44 \%$ (Table 3, Panel B), which is due to a decrease in the tail risk. As we can see from the Table 2, the VaR of the random hedge fund portfolio is smaller than the VaR of most other assets. Exceptions are funds of funds, the risk free asset, as well as some counter cyclical assets like the gold index and portfolio of put options.

\subsection{Conditioning on in sample information improves performance}

In our third hypothesis, we want to assess to what extent we can improve upon the hedge fund portfolio strategy by conditioning on in sample information during the last 24 months. We use three sets of conditioning information in turn: performance measures, hedge fund investment styles, and pension fund investment styles.

When conditioning on performance measures, we use the previous 24 months of hedge fund returns to compute the different measures. The other alternative assets we do not investigate any further since the hedge fund portfolio strategy performs much better than all of the alternative strategies. Instead of picking random hedge funds for addition to the original pension fund portfolio, we now pick hedge funds from the set with the highest $5 \%$ of measures (lowest $5 \%$ for kurtosis and standard deviation).

Our comparisons are computed with respect to the random hedge fund portfolio strategy based on all available hedge funds. The results are summarized in Table 4. A sort based on the highest in sample MPPM yields an improvement in $\triangle M P P M$ of $0.26 \%{ }^{15}$ Interestingly, three other performance measures perform similarly: a sort based on the mean yields $0.25 \%$, a sort based on the alpha yields $0.31 \%$, and a sort based on ASSD yields $0.25 \%$. The latter is consistent with the findings of Bali, Brown, and Demirtas (2013), who find that ASD and MPPM provide very similar rankings. It emerges that all four performance measurements benefit strongly from a higher mean and thus perform similarly. Sorts by other ratios perform worse $(0.100 .20 \%)$. Higher moments such as kurtosis $(0.01 \%)$ and standard deviation $(0.00 \%)$ do not improve upon the use of portfolios of random hedge fund. The explanation is that the standard deviation of a hedge fund does not account for covariation with the original pension fund portfolio, a problem which also affects, to a lesser degree, skewness.

As another set of conditioning information, we use the largest self reported investment styles in the hedge fund database. We present the results in Table 5. The investment style that gives the highest improvement in terms of $\triangle M P P M$ is the CTA/managed futures style with a $\triangle M P P M$ of $0.32 \%$ and a zero $p$ value. This $\triangle M P P M$ is measured in addition to the baseline $\triangle M P P M$ of $0.79 \%$ for adding a random hedge fund portfolio to pension funds. Thus, by adding solely CTAs, the average pension fund adds a total $\triangle M P P M$ of $1.11 \%$. The good performance of CTA funds is consistent with Kat (2004) and Rollinger (2012), who show empirically that investing in these funds reduces the overall risk at limited costs. CTAs are able to reduce the volatility of stock and bond portfolios to a greater degree than other strategies and without significant negative effects on the skewness and kurtosis (Kat, 2004). According to the Barclays Capital (2012) research report, institutional investors value CTA funds mainly for the following features: low correlation with conventional assets, diversification potential, and risk mitigation. The runner up styles after CTA/managed futures are sector trading, distressed, and global macro.

The good performance of distressed hedge funds is not surprising. Due to the illiquidity of dis tressed markets, hedge funds purchase distressed securities at deep discounts. Gains from this strategy were especially pronounced during the early 2000s when the lending standards were low. However, as opposed to CTAs that provide stable outperformance throughout our sample, distressed funds tend to profit more during bull markets.

\footnotetext{
${ }^{15}$ For completeness, we report $p$-values of the t-tests for all pairs of conditional strategies in Table IA.1.
} 
Table 4

Conditional strategies: performance measures.

The table presents the out-of-sample results of the MPPM analysis for conditional strategies. The conditional sets include portfolios of hedge funds with the highest $5 \%$ in-sample performance measures (lowest $5 \%$ for kurtosis and standard deviation). We measure the (annualized) average $\triangle$ MPPM over a random hedge fund portfolio as the MPPM of the alternative asset strategy ( $90 \%$ invested into the original pension fund and $10 \%$ invested into one of the alternative assets: risk-free rate, real estate, commodity, foreign equity, random fund of funds, or a random portfolio of mutual funds) minus the MPPM of the random hedge fund strategy ( $90 \%$ invested into the original pension fund and 10\% invested into a random portfolio of hedge funds).

\begin{tabular}{|c|c|c|}
\hline Strategy in-sample & $\begin{array}{l}\text { avg. } \triangle M P P M \text { over a ran- } \\
\text { dom hedge fund portfolio }\end{array}$ & $p$-value \\
\hline Highest $\triangle M P P M$ & 0.26 & 0.00 \\
\hline Highest change in ratio, Sharpe (1966) & 0.12 & 0.00 \\
\hline Highest change in Information Ratio & 0.11 & 0.00 \\
\hline Highest change in Sortino Ratio (1991) & 0.11 & 0.00 \\
\hline $\begin{array}{l}\text { Highest change in ratio, Sortino, v.d. } \\
\text { Meer, and Plantinga (1999) }\end{array}$ & 0.11 & 0.00 \\
\hline $\begin{array}{l}\text { Highest measure, Treynor and Mazuy } \\
\text { (1966) }\end{array}$ & 0.11 & 0.00 \\
\hline $\begin{array}{l}\text { Highest measure, Henriksson and } \\
\text { Merton (1981) }\end{array}$ & 0.11 & 0.00 \\
\hline Highest alpha, Fung and Hsieh (2001) & 0.31 & 0.00 \\
\hline $\begin{array}{l}\text { Almost Second-Order Stochastic } \\
\text { Dominance }\end{array}$ & 0.25 & 0.00 \\
\hline Lowest change in kurtosis & -0.01 & 0.48 \\
\hline Highest change in skewness & 0.20 & 0.00 \\
\hline Highest change in mean & 0.25 & 0.00 \\
\hline Lowest change in standard deviation & 0.00 & 0.86 \\
\hline
\end{tabular}

Table 5

Conditional strategies: hedge fund investment styles.

The table presents the out-of-sample results of the MPPM analysis for conditional strategies. The conditional sets include the largest reported investment styles of hedge funds. We measure the (annualized) average $\triangle M P P M$ over a random hedge fund portfolio as the MPPM of the alternative asset strategy (90\% invested into the original pension fund and $10 \%$ invested into one of the alternative assets: risk-free rate, real estate, commodity, foreign equity, random fund of funds, or a random portfolio of mutual funds) minus the MPPM of the random hedge fund strategy ( $90 \%$ invested into the original pension fund and $10 \%$ invested into a random portfolio of hedge funds).

\begin{tabular}{lcc}
\hline Strategy in-sample & $\begin{array}{c}\text { avg. } \mathbf{M} \text { MPPM over a random hedge fund } \\
\text { portfolio }\end{array}$ & $\boldsymbol{p}$-value \\
\hline Emerging markets & -0.21 & 0.00 \\
Long/short equity & -0.04 & 0.00 \\
Fixed income & -0.16 & 0.00 \\
Global macro & 0.08 & 0.00 \\
Distressed & 0.10 & 0.00 \\
CTA/Managed futures & 0.32 & 0.00 \\
Event driven & 0.02 & 0.24 \\
Multi-strategy & 0.03 & 0.02 \\
Sector-trading & 0.12 & 0.00 \\
\hline
\end{tabular}

Similar to CTAs, global macro hedge funds typically demonstrate low correlation with equities. Even though the global macro performed on a stand alone basis can be a very volatile strategy, addition to a portfolio with a large share of equities decreases the overall risk substantially. Multi strategy, event driven, and equity long/short are styles with middling $\triangle M P P M$ between ( $0.04 \%$ and $0.03 \%$ ). The least beneficial styles are fixed income and emerging markets with significantly negative $\triangle M P P M s(0.16 \%$ and $0.21 \%$ ). Strömqvist (2007) has shown that emerging market hedge funds are mainly investing in long equity positions. Bris et al. (2007) also claim that the short positions in emerging markets are limited. Since many of the pension funds in our database are exposed to equities, adding emerging 
Table 6

Conditional strategies: pension fund investment styles.

The table presents the out-of-sample results of the MPPM analysis for conditional strategies. The conditional sets include four investment styles of the pension funds (equity, fixed income, allocation, real estate, and alternative). We measure the (annualized) average $\triangle$ MPPM over a random hedge fund portfolio as the MPPM of the alternative asset strategy (90\% invested into the original pension fund and $10 \%$ invested into one of the alternative assets: risk-free rate, real estate, commodity, foreign equity, random fund of funds, or a random portfolio of mutual funds) minus the MPPM of the random hedge fund strategy (90\% invested into the original pension fund and $10 \%$ invested into a random portfolio of hedge funds).

\begin{tabular}{|c|c|c|}
\hline Strategy in-sample & $\begin{array}{c}\text { avg. } \triangle M P P M \text { over a random hedge fund } \\
\text { portfolio }\end{array}$ & $p$-value \\
\hline Equity & 0.20 & 0.00 \\
\hline Fixed income & -0.38 & 0.00 \\
\hline Allocation & -0.11 & 0.00 \\
\hline Real estate & -0.32 & 0.00 \\
\hline Alternative & -0.07 & 0.00 \\
\hline
\end{tabular}

Table 7

Persistence analysis.

The table presents estimated slope coefficients $(b)$ from two linear regressions: $\triangle M P P M_{2 i} \quad a_{M P P M}+b_{M P P M} \triangle M P P M_{1 i}+\omega_{i}$ and $\alpha_{2 i} \quad a_{\alpha}+b_{\alpha} \alpha_{1 i}+v_{i}$. It also provides the $p$-values of the $t$-test on the significance of the $b$ estimate. $\triangle M P P M_{1 i}\left(\triangle M P P M_{2 i}\right)$ is first calculated for each pension fund during consecutive periods ( $\triangle M P P M_{1 i}$ during the formation period and $\triangle M P P M_{2 i}$ during the evaluation period). $\triangle M P P M_{1 i}\left(\triangle M P P M_{2 i}\right)$ then is stacked in order to estimate the overall slope coefficient. We proceed similarly for the alphas. By stacking the regressions, we assume that the slope coefficients are constant across periods. Standard errors are Newey-West corrected.

\begin{tabular}{lccccc}
\hline \multirow{2}{*}{$\begin{array}{l}\text { Sample size (formation period/evalua- } \\
\text { tion period) }\end{array}$} & \multicolumn{2}{c}{$\Delta \mathbf{M P P M}$} & & \multicolumn{2}{c}{ Alpha } \\
\cline { 2 - 5 } & $\boldsymbol{b}$ & $\boldsymbol{t}$-stat & & $\boldsymbol{b}$ & $\boldsymbol{t}$-stat \\
\hline 12 months/12 months & 0.11 & 20.87 & -0.02 & -3.19 \\
24 months/24 months & -0.08 & -10.78 & -0.05 & -8.09 \\
36 months/36 months & -0.48 & -16.95 & -0.13 & -15.90 \\
\hline
\end{tabular}

market hedge funds does not contribute to a stronger performance. Moreover, long equity positions restrict emerging markets hedge funds to exploit the markets during downturns.

As a final set of conditioning information, we use the investment styles of the pension funds. Our results in Table 6 suggest that pension funds with large allocations in equities profit the most from adding a portfolio of hedge funds ( $\triangle M P P M$ of $0.20 \%$ ), while pension funds specializing in fixed income investments benefit the least ( $\triangle M P P M$ of $0.38 \%$ ). Again, the total benefit of adding a random hedge fund portfolio to pension funds specializing in equity investments is a $\triangle M P P M$ of $0.99 \%(=0.79 \%+$ $0.20 \%$ ) and only $0.41 \%$ for pension funds specializing in fixed income. Since the funds in our sample may be constrained from investing into hedge funds, we conduct a robustness check where we use only pension funds that are allowed to invest into alternative investments. These results are pre sented in Table 6 and confirm our main findings.

\subsection{Total benefit is more persistent than alpha}

As there is considerable disagreement about the persistence of alpha, we are keen to show that $\triangle$ MPPM is more persistent than alpha. We adopt a methodology commonly used in alpha persistence analysis when we estimate the regressions in (Eqs. (3) and 4). Cross sectional $\triangle$ MPPMs (alphas) estimated in one 12 (24 or 36 ) month period are regressed on cross sectional $\triangle M P P M$ s (alphas) estimated in a subsequent 12 ( 24 or 36 ) month period.

We show in Table 7 the estimated slope coefficients for the stacked regressions for different sample sizes. When the sample size is short (12 months), the aggregate slope estimates in the $\triangle M P P M$ regressions are significantly positive ( 0.11 for 12 months). On the contrary, alpha has sig nificantly negative aggregate slope coefficients ( 0.01 or 0.02 ). 
However, increasing the sample size to 24 or 36 months shows significant anti persistence in $\triangle M P P M$ and alpha, which could be due to mean reversion in estimated performance measures over longer periods.

\section{Robustness}

We perform several robustness checks for the main unconditional results reported in Table 2 (Hypotheses 1 and 2). Our results are robust to adding single random hedge funds instead of a random portfolio of hedge funds, using de smoothed hedge fund returns, changes in the risk aversion coefficient of the MPPM calculation, and a number of smaller methodological changes.

Even though institutional investors such as pension funds typically augment their original port folio with a portfolio of some 20 hedge funds, we test whether adding a single hedge fund is still beneficial. We measure the $\triangle M P P M$ of the alternative assets over the addition of a single random hedge fund and report the results in Table IA.2 in the Internet Appendix. $\triangle M P P M$ s are about 0.06\% lower than in Table 2 for all alternative assets. This difference quantifies the added benefit of diversification by using a random portfolio of hedge funds as opposed to a single random hedge fund.

We de smooth returns as suggested in Getmansky et al. (2004). De smoothed returns are char acterized by higher volatility than the smoothed (observed) returns. Therefore, it is not surprising that the $\triangle M P P M$ values in Table IA.3 are slightly smaller by about $0.01 \%$ than in Table 2 .

When computing $\triangle M P P M$ in our base case, we set the risk aversion coefficient of the power utility function in Eq. (2) to $\gamma=3$. We take this to be a fairly typical value for a diversified investor. We replicate the main results with $\gamma=4$ (Table IA.4, Panel A) and $=1$ (Table IA.4, Panel B). Our results remain largely unchanged and strongly significant. In general, the move to less risk aversion $(\gamma=1)$ narrows the gap between the random portfolio of hedge funds and the other alternative assets by around $0.10 \%$, while the move to more risk aversion $(\gamma=4)$ widens this gap by around $0.20 \%$. Almost all $\triangle M P P M s$ remain negative.

We change a number of methodological choices and find that our main results in Table 2 do not change much and stay significant. All results are relegated to the Internet Appendix. We use:

a) A different in sample size of 36 returns instead of 24 returns, see Table IA.5.

b) Different weights for additions to the pension fund portfolio of $5 \%$ and $25 \%$ (instead of $10 \%$ in the base case), see Table IA.6.

c) Only hedge funds open to new investment instead of all hedge funds, see Table IA.7.

We find that our results are very stable with respect to all these changes.

\section{Conclusion}

Historically, pension funds explored alternative assets beyond stocks and bonds only on a limited scale. Possibly driven by the recent financial crisis, those stakes have been increased to around $10 \%$ of the typical pension fund portfolio. Still, we know little about which alternative assets to add and how to account for their total benefits to the pension fund, which might include diversification benefits, the addition of positive skewness, and the avoidance of tail risk. We advocate the use of (changes in) the manipulation proof performance measure ( $\triangle M P P M)$ of Goetzmann et al. (2007) for performance measurement. The main traditional performance measures, the Sharpe ratio and the Fung and Hsieh (2001) factor model alpha, are both problematic: it is assumed with the Sharpe ratio that returns are normally distributed, and factor models suffer from poorly estimated parameters, low persistence, and low explanatory power. Still, we find in the end that our findings remain when using the Sharpe ratio or a factor model instead of $\triangle M P P M$.

Using a large merged database of hedge funds returns from February 1994 to December 2012 and a sample of U.K. pension funds (including mutual funds that are suitable for pension investing), we analyze strategies where we invest $90 \%$ in a pension fund and $10 \%$ in an alternative asset. We compare 
this strategy to an investment of $100 \%$ into the pension fund. We find that using a random portfolio of hedge funds as an alternative asset improves the average pension fund performance by an annualized $\triangle M P P M$ of $0.79 \%$, which is superior to adding most other alternative assets such as foreign equity, real estate, the risk free rate, a random portfolio of mutual funds, commodities, a random fund of funds, as well as some counter cyclical and non cyclical assets such as portfolios of OTM put options with targeted market beta of 1, an index of consumer staples, and an inverse ETF. We also find that adding a gold index is even more beneficial than adding a random hedge fund.

This advantage can be further improved upon by conditioning on in sample $\triangle M P P M$ (yielding an additional $\triangle$ MPPM of $0.26 \%$ ). Hedge funds selected based on their past MPPM outperform all other assets, including the gold index. However, some other conditioning information exhibits similar results. In terms of hedge fund styles, the highest performance gain comes from conditioning on the $\mathrm{CTA} /$ managed futures style, while adding hedge funds that heavily trade in equities is less beneficial. We also show that hedge funds are more helpful for the performance of pension funds than tradi tional asset classes during times of distress (recessions) when the $\triangle M P P M$ increases by up to $3.07 \%$ (based on the NBER definition of recessions) and by $2.44 \%$ (based on the so called technical indicator of recessions for the U.K.).

For short time spans of 12 months, the persistence of total benefits is significantly positive while it is insignificant for alpha. Increasing the time spans is associated with anti persistence, which could be due to mean reversion in performance over the long run. All our results are robust to a wide range of changes to the methodology.

\section{Appendix A}

We collect all formulas of our performance measures in this appendix. $\sim r$ is the excess return, $\sim r_{b}$ is the return of some benchmark, $\sim m_{t}$ is the excess market return, and MAR is the minimum acceptable returns.

\begin{tabular}{|c|c|}
\hline Measure & Formula \\
\hline $\begin{array}{l}\text { Almost Stochastic } \\
\text { Dominance } \\
\text { (Second Order) }\end{array}$ & $\begin{array}{c}U_{2}^{*}\left(\varepsilon_{2}\right)=\left\{u \in U_{2} ; \quad u^{\prime \prime}(s) \leq \operatorname{Inf}\left\{\quad u^{\prime \prime}(s)\right\}\left[\begin{array}{ll}\frac{1}{\varepsilon_{2}} & 1\end{array}\right], \forall s \in(\text { Min, Max })\right\} \\
\text { For all } u \in U_{2}^{*}, H \text { dominates } L \text { by ASSD, iff } \varepsilon_{2} \leq \varepsilon_{2}^{*} \text {, where } \\
\varepsilon_{2}=\frac{\int_{R_{2}}\left[F_{H}(s)-F_{L}(s)\right] d s}{\int_{\text {Min }}^{\text {Max }}\left|F_{H}(s)-F_{L}(s)\right| d s^{\prime}} \\
R_{2}\left(F_{H}, F_{L}\right)=\left\{s \in R_{1}\left(F_{H}, F_{L}\right): \int_{0}^{r}\left[F_{L}(s) \quad F_{H}(s)\right] d s<0\right\}, R_{1}\left(F_{H}, F_{L}\right)=\left\{s \in\left(r_{1}, r_{2}\right): F_{L}(s)<F_{H}(s)\right\}\end{array}$ \\
\hline Sharpe (1966) & $\frac{E[r]}{\sqrt{ } \operatorname{Var}[r]}$ \\
\hline $\begin{array}{l}\text { Sortino and van } \\
\text { der Meer (1991) }\end{array}$ & $\frac{E[r]}{\sqrt{E\left[(\operatorname{Min}(r, 0))^{2}\right]}}$ \\
\hline $\begin{array}{l}\text { Sortino, van der } \\
\text { Meer, and } \\
\text { Plantinga (1999) }\end{array}$ & $\frac{E[\operatorname{Max}(r, 0)]}{\sqrt{E\left[(\operatorname{Min}(r, 0))^{2}\right]}}$ \\
\hline Information Ratio & $\frac{E\left[r-r_{b}\right]}{\sqrt{ } \operatorname{Var}\left[r-r_{b}\right]}$ \\
\hline $\begin{array}{l}\text { Henriksson and } \\
\text { Merton (1981) }\end{array}$ & $\gamma_{2}$ as estimated in : $\tilde{r}_{t}=\gamma_{0}+\gamma_{1} \tilde{m}_{t}+\gamma_{2} \tilde{w}_{t}+\varepsilon_{t} ; \tilde{w}_{t}=\operatorname{Max}\left(\tilde{m}_{t}, 0\right)$ \\
\hline $\begin{array}{l}\text { Treynor and } \\
\text { Mazuy (1966) }\end{array}$ & $\gamma_{2}$ as estimated in : $\tilde{r}_{t}=\gamma_{0}+\gamma_{1} \tilde{m}_{t}+\gamma_{2} \tilde{w}_{t}+\varepsilon_{t} ; \tilde{w}_{t}=\tilde{m}_{t}^{2}$ \\
\hline
\end{tabular}




\section{Appendix B. Supplementary material}

Supplementary data associated with this article can be found in the online version at http://dx.doi. org/10.1016/j.finmar.2016.06.002.

\section{References}

Ackermann, Carl, McEnally, Richard, Ravenscraft, David, 1999. The performance of hedge funds: risk, return, and incentives. J. Financ. 54, 833-874.

Agarwal, Vikas, Naik, Narayan Y., 2004. Risks and portfolio decisions involving hedge funds. Rev. Financ. Stud. 17, 63-98.

Agarwal, Vikas, Naik, Narayan Y., 2000. Multi-period performance persistence analysis of hedge funds. J. Financ. Quant. Anal. 35 , 327-342.

Amin, Gaurav S., Kat, Harry M., 2002. Diversification and yield enhancement with hedge funds. J. Altern. Investments 5, 50-58. Amin, Gaurav S., Kat, Harry M., 2003. Hedge fund performance 1990-2000: do the money machines really add value? J. Financ. Quant. Anal. 38, 251-274.

Bali, Turna G., Demirtas, K. Ozgur, Levy, Haim, Wolf, Avner, 2009. Bonds versus Stocks: Investors' age and risk taking? J. Monet. Econ. 56, 817-830.

Bali, Turan G., Stephen J. Brown, K. Ozgur Demirtas, 2012, Investing in Stock Anomalies? Working Paper (Robert Emmett McDonough School of Business, Georgetown University).

Bali, Turan G., Brown, Stephen J., Demirtas, K. Ozgur, 2013. Do hedge funds outperform stocks and bonds? Manag. Sci. 59, 1887-1903.

Barclays Capital, 2012, Trending Forward: CTAs/Managed Futures, Hedge Fund Pulse Report.

Berk, Jonathan B., and Jules H. van Binsbergen, 2013, Measuring managerial skill in the mutual fund industry, Working Paper (Graduate School of Business, Stanford University).

Berk, Jonathan B., Green, Richard C., 2004. Mutual fund flows and performance in rational markets. J. Political Econ. 112, 1269-1295.

Bris, Arthur, Goetzmann, William N., Zhu, Ning, 2007. Efficieny and the bear: Short sales and markets around the world. J. Financ. 62, 1029-1079.

Brown, Stephen J., Fraser, Thomas L., Liang, Bing, 2008. Hedge fund due diligence: a source of alpha in a hedge fund portfolio strategy. J. Invest. Manag. 6, 23-33.

Brunnermeier, Markus K., Nagel, Stefan, 2004. Hedge funds and the technology bubble. J. Financ. 59, 2013-2040.

Capocci, Daniel, Hübner, Georges, 2004. An analysis of hedge fund performance. J. Empir. Financ. 11, 55-89.

Constantinides, George M., Jackwerth, Jens C., Savov, Alexi Z, 2013. The puzzle of index option returns. Rev. Asset Pricing Stud. 3, 229-257.

Davidson, Russell, Duclos, Jean-Yves, 2000. Statistical inference for stochastic dominance and for the measurement of poverty and inequality. Econometrica 68, 1435-1464.

Edwards, Franklin R., Caglayan, Mastafa O., 2001. Hedge fund performance and manager skill. J. Futur. Mark. 21, 1003-1028.

Ferson, Wayne E., Lin, Jerchern, 2013. Alpha and performance measurement: the effects of investor disagreement and heterogeneity. J. Financ. 69, 1565-1596.

Fung, William, Hsieh, David A., 2001. The risk in hedge fund strategies: theory and evidence from trend followers. Rev. Financ. Stud. 14, 313-341.

Fung, William, Hsieh, David A., Naik, Narayan Y., Ramadorai, Tarun, 2008. Hedge funds: performance, risk, and capital formation. J. Financ. 63, 1777-1803.

Getmansky, Mila, Lo, Andrew W., Makarov, Igor, 2004. An econometric model of serial correlation and illiquidity in hedge fund returns. J. Financ. Econ. 74, 529-609.

Glode, Vincent, Green, Richard C., 2011. Information spillovers and performance persistence for hedge funds. J. Financ. Econ. $101,1-17$.

Goetzmann, William N., Ingersoll, Jonathan, Spiegel, Matthew, Welch, Ivo, 2007. Portfolio performance manipulation and manipulation-proof performance measures. Rev. Financ. Stud. 20, 1503-1546.

Henriksson, Roy D., Merton, Robert C., 1981. On market timing and investment performance. II. statistical procedures for evaluating forecasting skills. J. Bus. 54, 513-533.

Hodder, James E., Jackwerth, Jens C., Kolokolova, Olga, 2013. Recovering delisting returns of hedge funds. J. Financ. Quant. Anal. 49, 797-815.

International Monetary Fund, 2004, Global financial stability report.

Jagannathan, Ravi, Malakhov, Alexey, Novikov, Dmitry, 2010. Do hot hands exist among hedge fund managers? an empirical evaluation. J. Financ. 65, 217-255.

Kao, Duen-Li, 2002. Battle for alphas: hedge funds versus long-only portfolios. Financ. Anal. J. 58, 16-36.

Kat, Harry M., 2004. Managed futures and hedge funds: a match made in heaven. J. Invest. Manag. 2, 1-9.

Kosowski, Robert, Naik, Narayan Y., Teo, Melvyn, 2007. Do hedge funds deliver alpha? A bayesian and bootstrap analysis. J. Financ. Econ. 84, 229-264.

Leshno, Moshe, Levy, Haim, 2002. Preferred by "all" and preferred by "most" decision makers: almost stochastic dominance. Manag. Sci. 48, 1074-1085.

Levy, Haim, Leshno, Mosche, Leibovitch, Boaz, 2010. Economically relevant preferences for all observed epsilon. Ann. Oper. Res. $176,153-178$.

Lhabitant, Francois S., Michelle Learned, 2002. Hedge fund diversification: how much is enough? Working Paper (Kedge Capital Fund Management, EDHEC Business School)

Liang, Bing, 1999. On the performance of hedge funds. Financ. Anal. J. 55, 72-85.

Lo, Andrew W., 2002. The statistics of Sharpe ratios. Financ. Anal. J. 58, 36-52. 
Naik, Narayan Y., Ramadorai, Tarun, Strömqvist, Maria, 2007. Capacity constraints and hedge fund strategy returns. Eur. Financ. Manag. 13, 239-256.

Myners, Paul, 2001. Institutional Investment in the United Kingdom: A Review, /webarchive.nationalarchives.gov.uk/ 20130129110402/http://www.hm-treasury.gov.uk/media/2F9/02/31.pdf〉.

Preqin, 2014. The 2014 Preqin Global Hedge Fund Report. 〈https://www.preqin.com/docs/reports/The_2014_Preqin_Global_ Hedge_Fund_Report_Sample_Pages.pdf).

Rollinger, Thomas N., 2012. Revisiting Kat's managed futures and hedge funds: a match made in heaven, Working Paper (Sunrise Capital Partners).

Sharpe, William F., 1966. Mutual fund performance. J. Bus. 39, 119-138.

Sortino, Frank A., van der Meer, Robert, 1991. Downside risk. J. Portf. Manag. 17, 27-31.

Sortino, Frank A., van der Meer, Robert, Plantinga, Auke, 1999. The Dutch triangle. J. Portf. Manag. 26, 50-57.

Stewart, Fiona, 2007. Pension fund investment in hedge funds, Working Paper (OECD Working Papers on Insurance and Private Pension Funds).

Strömqvist, Maria, 2007. Should you invest in emerging market hedge funds? Working Paper (Stockholm School of Economics). Treynor, Jack L., Mazuy, Kay L., 1966. Can mutual funds outguess the market? Harv. Bus. Rev. 44, 131-136. 